declared that the governmont accepts, in general, the Swann committee's proposals for the control of antibiotics but that "some of the committee's more detailed recommendations and longer term proposals on research and veterinary epidemiology will need further study". Manufacturers will be given a reasonable period of grace to run down feed stocks which contain the prohibited "therapeutic" antibiotics; these include penicillin, the tetracyclines, tylosin, the sulphonamides and certain nitrofurans.

\section{OPEN UNIVERSITY}

\section{How to Get a Degree}

The Open University will accept applications from prospective students in January 1970, and will begin in earnest a year later. It seems that the plans have been made for a comprehensive selection of courses, and the student will graduate by building up a number of credits, each of which is awarded for successful completion of a one-year part-time course. Six credits are needed to qualify for a BA degree, and eight for a BA degree with honours. Because no more than two courses may usually be taken in any one year, the minimum period for achieving a degree will be three years, but it is expected that many students will take courses one at a time over several years.

Tuition will consist of a system of correspondence courses, radio and television programmes, a summer school, and regionally organized counselling. Students will probably spend about ten hours a week on their studies, including an hour's television and radio courses. The first year will be spent on "foundation" courses, which will be repeated every year for new students, while successful students will carry on to second, third and fourth level courses. Two credits from foundation courses must be achieved before a student can qualify for a degree, and an honours qualification will include credits from third or fourth levels. Apart from these restrictions, a student will be free to choose his courses, and he will therefore be able to combine a variety of subjects, for example, science and humanities. This is one obvious advantage that the Open University can offer, compared with conventional universities.

The university later hopes to introduce postgraduate and post-experience courses, and also "updating" courses which will be intended for people wishing to keep pace with advances in their professions. In addition, already qualified teachers will be awarded one credit for every year that they have spent in a college of education, thus enabling them to qualify for a BA degree on successful completion of only three courses.

Students will be accepted for the 25,000 places that the Open University hopes to have available, on the basis of their occupation, age, preparedness, region, and the subjects which they hope to study, but Dr Walter Perry, Vice-Chancellor of the Opon University, said that the weighting given to each of these criteria could not yet be determined. The cost of qualifying for a degree will vary according to whether a student takes one or two courses a year. There will be an initial registration fee of $£ 10$ and a single foundation course will cost $£ 40$. This fee will be payable in April, however, to allow students, who find that they do not want to carry on, to drop out before they have committed themselves financially. Second, third and fourth level courses cost $\mathfrak{f 2 0}$, and it is therefore possible for a student to acquire a degree in three years for $£ 140$, or a BA with honours for $£ 180$, inclusive of accommodation fees at the summer schools.

\section{SEISMOLOGY \\ Setting the Moon Ringing}

\section{from our Geophysics Correspondent}

IT is, of course, too early to do more than say "whoopee" and jump on the speculative bandwagon after the remarkable results from the lunar seismometer last weok. We have been lucky in getting a comprehensive press coverage so soon, with comments from Drs Latham, Ewing and Press, but newspaper descriptions can only titillate the imagination-all geophysicists and planetary physicists will be itching to see the records for themselves. The hard facts that we have so far are that when the ascent stage of Intrepid was rammed back to the Moon's surface, it produced a crater twenty feet across and two feet deep, some forty miles from the Apollo 12 seismometer. The impact generated seismic waves which continued for thirty to forty minutes.

On Earth, this would be unthinkable. An explosion of modest size on the Earth's surface-perhaps a few tens of tons-could simulate this event, but a recording station a mere forty miles away would record signals for perhaps a minute or two as the surface waves passed by. After that there would be silence-and not just because the instrument would be not sensitive cnough but because the next arrival of energy would be an hour or more later, from surface waves that had gone round the Earth the other way, and these would be so heavily damped by imperfections in the elasticity of the Earth (which has a $Q$ between 200 and 500 ) that for practical purposes the waves would be completely blotted out.

How is the Moon different? If we assume as a starting point that the elastic properties are comparable, surface waves should get round the antipodal path much more quickly because the radius is smaller. These could certainly contribute to the signal, provided the an-elastic properties are not as marked as on Earth. For example, the presence of a low seismic velocity layer on Earth, probably the result of partial melting between 100 and $300 \mathrm{~km}$, is widely believed also to lead to a low $Q$ layer. This region of high seismic wave absorption dominates the attenuation of surface waves. On the Moon, things may be different. If there is no partial melting near the surface-and there is no reason. why there should be an analogy with the Earth-then it is possible that $Q$ is high throughout the Moon-maybe as high as a thousand. The Moon is then nearly as resonant as a bell, and any small disturbance will set it ringing for a very long time.

It would be foolish, however, to state at this stage that the results unequivocally favour the "cold Moon" theory, as one or two enthusiasts have already claimed. Much of the Earth's crust has a $Q$ in the region of a thousand and the low $Q$ zone may be a coincidence of thermal conditions, pressure and petrology. It is impossible to say at this stage whether the apparent absence of lunar absorption has any bearing on internal lunar temperatures.

Without the seismograms themselves, we can only 
guess, and a highly resonant Moon is the first idea that springs to mind. It is not the only possible explanation, however. Perhaps the impact triggered off numerous fractions which acted as an earthquake sequence. Explosions occasionally trigger earthquakes, but the only large scale triggering on Earth has been after megaton tests in Nevada (Nature, 223, $773 ; 1969)$. By analogy the Moon should not be expected to quake after such a minor impact, but who knows? Exciting as the result is, a certain amount of unwilling suspension of judgment is necessary.

Whatever the conclusions reached from the smashdown records, it does seem at first sight as if the signals recorded by Apollo 12's seismometer before it went off the air were of entirely local origin. Many had thought they were probably landslides or venting from the lunar launchpad. This view is now strengthened by the knowledge that even fairly modest lunar events generate so substantial a scismic record. So porhaps there are no moonquakes worth mentioning. If so, exploration of the lunar interior will need artificial sources. It is a pleasant relief that nothing enormous will be needed. The idea of a nuclear explosion on the Moon "to see what happens" has already been semiseriously canvassed. At least there will be no demand from lunar seismologists for such fearfully large and politically nonsensical experiments.

\section{IONOSPHERE}

\section{Petrel on Target}

\section{from our Astronomy Correspondent}

$\mathrm{BY}$ all accounts, the success of an investigation into the auroral ionosphere earlier this year has been a good advertisement for the British Petrel rocket built by Bristol Aerojet Ltd. Eight Petrels were launched during February and March in a campaign organized by the Science Research Council which took place at the European Space Research Organization (ESRO) range at Kiruna in Sweden. Preliminary scientific results from the campaign were discussed last week at a meeting in the Department of Physics at the University of Sheffield. For the first time in the history of the range, all the rockets in a campaign fell within the designated area. In the past, rockets such as Skylark and Arcas have been launched from Kiruna, and firings have been known to land not only outside the range but sometimes outside Sweden. Rockets have fallen in Finland, which meets Norway and Sweden not far from Kiruna. Despite reaching a greater height than normal-150 km instead of $125 \mathrm{~km}$-because of a combination of meteorological factors and the altitude of the range, all the Petrels remained substantially on course, and it seems that their performance might earn them a place in the ESRO armoury.

Although only 7.5 inches in diameter and small enough to be launched from a tube, Petrel can carry enough instrumentation to make most ionospheric scientists happy. And with one rocket per experiment they have made their contribution to a pleasant life on the range by ending the awkward problems of integrating experiments from different groups.

It is now becoming easier to measure electric fields in the ionosphere, and several groups were preoccupied with the techniques. What seems to be the most promising method so far was described by the group from the University of Birmingham (J. W. G. Wilson, J. H. Wager and C. P. van Zyl) and is based on measurements of the voltage difference between two spherical probes. Unfortunately, however, in the firing which they described the probes seem to have caused the rocket to precess more than normal, and the results are therefore not as good as they might have been. Another way to evaluate the field is to observe the drift of an artificial cloud of ions relative to a neutral cloud, and a joint team from the Universities of Sussex and Southampton (J. Hunter, G. Martelli, K. Martin and P. Rothwell) has been extending this method to lower altitudes than normal. Clouds released in the E-region often do not separate into neutral and ionized components, yet nevertheless it seems possible to estimate the electric field from the way the cloud deforms.

The Sheffield group (P. Beckingham, W. Gibbons. and T. R. Kaiser) is concerned with direct measurements of the fine structure of electron density in auroras which has been inferred from radar work. To do this the group has developed a Langmuir probe which in theory has a spatial resolution of a few tens of centimetres, but which in practice, because of telemetry limitations, has a height resolution of about $1.5 \mathrm{~m}$. The group is looking for the role in auroras of irregularities about a metre across and perhaps tens of metres long aligned along the magnetic field.

There is also the question of the mechanism that accelerates electrons to energies of tens of $\mathrm{keV}$ and leads to very bright aurorae. Another group at Southampton (P. Rothwell et al.) and a group from the Radio and Space Research Station (D. A. Bryant, G. M. Courtier and G. Bennet) have been looking at electrons of these energies at times when acceleration is believed to be taking place.

Oddly enough, informal discussions of the results of a campaign before anything is published is the exception rather than the rule and people are hoping that the Sheffield meeting will set a trend.

\section{APOLLO \\ New Broom on the Moon}

\section{from a Correspondent}

Now that the main task of Dr George Mueller, the National Aeronautics and Space Administration's Associate Administrator for Manned Space Flight, of getting an American safely on to the Moon by 1970 is accomplished, there is every justification for his retirement. This was announced on November 10, four days before the departure of Apollo 12.

NASA has praised his achievement handsomely in an announcement that reads a little like an epitaph. "It is due to Dr Mueller's creative leadership of the magnificent manned space flight organization that the flight of Apollo 11 in July 1969 achieved the national goal set in May 1961: the landing of men on the Moon and their safe return to Earth by the end of the decade." Dr Mueller, it is claimed, was responsible for the largest research, devclopment and operational programme ever undertaken by man. At its peak the Apollo programme employed 400,000 people. Among his principal achievements were devising methods for cutting down the interval between launchings. For 